\title{
"Keeping Moving": factors associated with sedentary behaviour among older people recruited to an exercise promotion trial in general practice
}

Ruth Heseltine ${ }^{1}$, Dawn A. Skelton ${ }^{4}$, Denise Kendrick³, Richard W. Morris², Mark Griffin', Deborah Haworth', Tahir Masud ${ }^{5}$ and Steve lliffe ${ }^{1^{*}}$

\begin{abstract}
Background: Sedentary behaviour is detrimental to health, even in those who achieve recommended levels of physical activity. Efforts to increase physical activity in older people so that they reach beneficial levels have been disappointing. Reducing sedentary behaviour may improve health and be less demanding of older people, but it is not clear how to achieve this. We explored the characteristics of sedentary older people enrolled into an exercise promotion trial to gain insights about those who were sedentary but wanted to increase activity.

Method: Participants in the ProAct65+ trial (2009-2013) were categorised as sedentary or not using a self-report questionnaire. Demographic data, health status, self-rated function and physical test performance were examined for each group. 1104 participants aged 65 \& over were included in the secondary analysis of trial data from older people recruited via general practice. Results were analysed using logistic regression with stepwise backward elimination.

Results: Three hundred eighty seven (35\%) of the study sample were characterised as sedentary. The likelihood of being categorised as sedentary increased with an abnormal BMI $\left(<18.5\right.$ or $\left.>25 \mathrm{~kg} / \mathrm{m}^{2}\right)$ (Odds Ratio $1.740, \mathrm{Cl}$ 1.248-2.425), ever smoking (OR 1.420, Cl 1.042-1.934) and with every additional medication prescribed (OR 1.069, Cl 1.016-1.124). Participants reporting better self-rated physical health (SF-12) were less likely to be sedentary; (OR 0.961, 0.936-0.987). Participants' sedentary behaviour was not associated with gender, age, income, education, falls, functional fitness, quality of life or number of co-morbidities.

Conclusion: Some sedentary older adults will respond positively to an invitation to join an exercise study. Those who did so in this study had poor self-rated health, abnormal BMI, a history of smoking, and multiple medication use, and are therefore likely to benefit from an exercise intervention.
\end{abstract}

Trial registration: ISRCTN reference: ISRCTN43453770

Keywords: Older people, Physical activity, Sedentary behaviour, Exercise promotion

\footnotetext{
*Correspondence: s.iliffe@ucl.ac.uk

${ }^{1}$ Department of Primary Care \& Population Health, University College London, Royal Free Campus, Rowland Hill St., London NW3 2PF, UK

Full list of author information is available at the end of the article
} 


\section{Background}

Sedentary behaviour (SB), conventionally defined as low energy-expenditure activity undertaken in a sitting or reclining position [1], is associated with adverse physical and mental health outcomes [2]. Sedentary behaviour appears to have deleterious health effects even where physical activity recommendations are met [3], and so sitting time is now recognised as a health risk factor independent of physical activity [4-6]. Older adults are most likely to be sedentary $[7,8]$.

Long periods of sitting are associated with a bigger waist circumference, depression and social isolation, and an increased risk of death [2]. Sedentary older adults are more likely to have the metabolic syndrome $[9,10]$, type 2 diabetes $[3,9,11]$, cardiovascular disease $[3,9,12]$, depression [13], lower bone mineral density [14], greater co-morbidity [13] and higher all-cause mortality [3, 15] than less sedentary older adults. Increased sedentary behaviour is further associated with functional limitations $[11,13,16]$, falls [13], poorer quality of life [17], experiencing severe pain [16] and lower likelihood of successful aging, measured across both physical and psychological domains [17]. Since the health risks are significant and far reaching, understanding the characteristics of sedentary individuals is potentially important in targeting health interventions to reduce sedentary behaviour.

Epidemiological studies have described the characteristics of sedentary older people. Increasing sedentary behaviour is associated with older age $[11,16,18]$, abnormal BMI $[9,12$, 16, 18-20], higher waist circumference [11], smoking $[11,12]$, living alone $[13,19]$, being unmarried $[11,12]$, lack of full-time employment [19] and lower levels of social support [16]. Occasionally the associations are conflicting. Sedentary behaviour has been shown to be more prevalent in women $[9,16]$, men $[11,12]$, neither sex [18], in those with lower education $[9,11,12,16,18,19]$, higher education [13], lower income [18] and higher income [13].

A small qualitative study by Chastin et al. [21] sheds light on the determinants, motivators and barriers older women express in relation to reducing sitting time. They attributed their sedentary behaviour to pain (predominantly musculo-skeletal), variable daily energy levels, external pressure from family and friends to undertake sitting activities and societal stereotypes of older people [21]. They also felt an entitlement to sit in older age, failed to recognise its objective harms and felt a sense of wellbeing from social sedentary activities [21]. Motivators to activity included pain relief (after sedentary periods), the necessity of household chores, in order to be useful to those around them and to relieve boredom \& depression [21]. They also identified environmental barriers to increasing activity including lack of standing activities for older people, poor weather, and lack of public resting places outside the home [21]. However, they felt that more community-based opportunities to be active would help them reduce their sedentary behaviour [21]. Whilst sometimes perceived as a hard to reach group, promotion of appropriately tailored exercise in older adults may prove both acceptable and effective in reducing sedentary behaviour.

To reduce sedentary behaviour we must first quantify it. Although challenging, several studies have quantified SB in older people [19, 22-24]. Whilst younger adults are engaged in SB during $60 \%$ [25] of their waking hours, older adults have been shown objectively (using accelerometry) to be sedentary more than $70 \%$ of the time [22, 24], for around $8-10 \mathrm{~h}$ of the waking day, and this increases linearly with age $[22,26]$. Conversely, selfreported SB is typically underestimated by as much as $50 \%$ [23, 27]. Espana-Romero et al. [28] showed that older people both overestimate their physical activity and underestimate their sedentary behaviour; men by $26 \%$ and women by $34 \%$ amounting to a difference of 4-6 h/day. Sedentary behaviour is thus commonplace in older adults and under-estimated by self-report.

This discrepancy between objective \& self-reported measures is explained by Van Uffelen et al. who demonstrate that older adults made judgements and generalisations when answering physical activity questionnaires [29]. Older people had difficulty in generating examples of sedentary activities beyond those explicitly listed. They were uncertain whether non-leisure sedentary activities should be included as sedentary (eating, driving etc.). They also generalised to a 'typical day' rather than giving a contemporaneous report of the day's activities [29]. Nonetheless, six activities have been shown to correlate best with SB; napping, reading, listening to music, watching $\mathrm{TV}$, having a hobby and talking to friends [30]. These can be used to estimate total sedentary time. The underestimate in self-reporting appears to correlate in a linear fashion with objectively measured sedentary behaviour [30]. Therefore, it is reasonable to measure SB using self-reported questionnaires like PASE (Physical Activity Scale for the Elderly) and adjust for under-reporting.

Understanding the volume of sedentary behaviour in older people and the negative associations with health leads to questions over the validity of physical activity targets. Guidelines focus on the attainment of moderatelyvigorous physical activity (MVPA) [4], even though older adults spend as little as $1 \%$ of their waking day in MVPA [22]. Exercise promotion for older adults should perhaps also aim at reducing SB [31] and displacing inactivity into light physical activity such as household chores, slow walking or light gardening [6]. These changes can increase the metabolic rate and energy expenditure markedly [32] and are associated with better physical health in adults aged 65+ [31]. Breaks to sedentary time are independently \& beneficially associated with lower waist circumference, 
BMI, triglyceride concentration and 2-h plasma glucose [33]. Reduction \& displacement of SB could be a useful target for older people's health promotion.

However, the literature on modifying sedentary behaviour is limited. Fitzsimons et al. [34] demonstrated an objective reduction in sedentary activity and an increase in activity in a small group of older adults following a motivational interview about reducing sedentary behaviour. Gardiner et al. found an objective reduction in sedentary time after a single-session of goal setting [35]. Magistro et al. [36] found that functional fitness improved in a group of sedentary older adults who undertook a 4 month small-group walking exercise programme. These smaller exploratory studies suggest that change is possible. However, when Stevens et al. [37] conducted a meta-analysis of activity-based interventions in general practice, only 6 suitable studies were found which were "heterogeneous and difficult to replicate or standardise". Further work is required to establish the effectiveness of interventions to reduce sedentary behaviour in older adults.

This study is novel because it explores the extent of sedentary behaviour in participants in an exercise intervention trial aimed at older people (65 and over) and carried out in general practice, and describes the characteristics associated with sedentary behaviour. The research questions were:1) Do sedentary older people join an exercise study? 2) What demographic, functional and health factors are associated with sedentary behaviour in this self-selected population of older people?

\section{Methods}

\section{Participants}

Data from the ProAct65+ trial were used in this study $[38,39]$. ProAct65+ was a pragmatic 3 arm parallel design cluster controlled trial of class-based exercise (Falls Management Exercise Programme, FaME), home based exercise (Otago Exercise Programme, OEP) and usual care (treatment as usual, TAU) amongst communitydwelling UK residents aged 65 years and over. The primary outcome was the proportion of participants meeting recommended levels of physical activity (30 mins of MVPA 5 days/week) 12 months after cessation of the intervention phase of the trial (FaME, OEP, TAU). The participants were interviewed and surveyed at regular intervals (baseline, 6, $12,18,24$ months post-randomisation) over a 2 year period (2009-2011). Ethical approval was obtained and consent details can be viewed in the full trial document [39].

General Practices were recruited in Nottingham, Derby and London, through the Primary Care Research Network. GPs screened for, and a researcher verified, eligible participants who were 65 years and over, independently mobile indoors and outdoors (with or without walking aid) and physically able to participate in group exercise classes. Exclusion criteria were already meeting recommended MVPA activity targets, having 3 or more falls in the previous year, unstable clinical conditions, inability to safely follow exercise instructions, not living independently, already receiving long term physiotherapy or receiving palliative care. Participants received an invitation letter from their usual GP. Of 20,507 people approached, 2752 adults expressed interest and 1256 gave consent to join the study [38]. One participants dropped out before attending for the baseline assessment and one subsequently withdrew all data from the study, leaving a sample of 1254. Complete PASE data was available for 1104, and this sample was used for the analysis of sedentary behaviour. Figure 1 shows the derivation of the sample.

\section{Data collection}

Multiple assessments were made at baseline. The measures considered in this study were selected according to the literature (see above), are listed below and described in detail elsewhere [38]. They consisted of: demographic data, functional assessments, health status and self-rated function, as shown in Table 1.

\section{Sedentary behaviour}

The dependent variable was sedentary behaviour (SB). An estimate measure of sedentariness was determined using two questions in the PASE questionnaire: "over the past 7 days, how often did you participate in sitting activities such as reading, watching TV or doing handicrafts?" \& "On average, how many hours per day did you engage in these sitting activities?" Since older people underestimate sedentary behaviour by self-report by up to $50 \%$ our operational definition of sedentariness was those who reported sitting-based activities for over $4 \mathrm{~h}$ on more than 5 days per week, corresponding to the $8+$ hours of objective sedentariness found by EspanoRomero and colleagues [28]. The non-sedentary group reported sedentary behaviour for fewer than $4 \mathrm{~h} /$ day on fewer than 5 days/week.

\section{Variable characterisation}

Category choices were determined by the characteristics associated with sedentary behaviour in epidemiological studies. Each examined variable was dichotomised as shown in Table 2, where possible applying standards from previous studies. Where no literature standard existed we dichotomised pragmatically. For example, smoking status was split into never- or ever- smokers since the majority of smokers had already quit but may have significant prior lifetime exposure. BMI was divided into normal or abnormal (encompassing both over- $\left(>25 \quad \mathrm{kgm}^{2}\right)$ \& under-weight $\left(<18.5 \quad \mathrm{kgm}^{2}\right)$ groups) as only a very small number of participants were underweight which we took to represent poor 


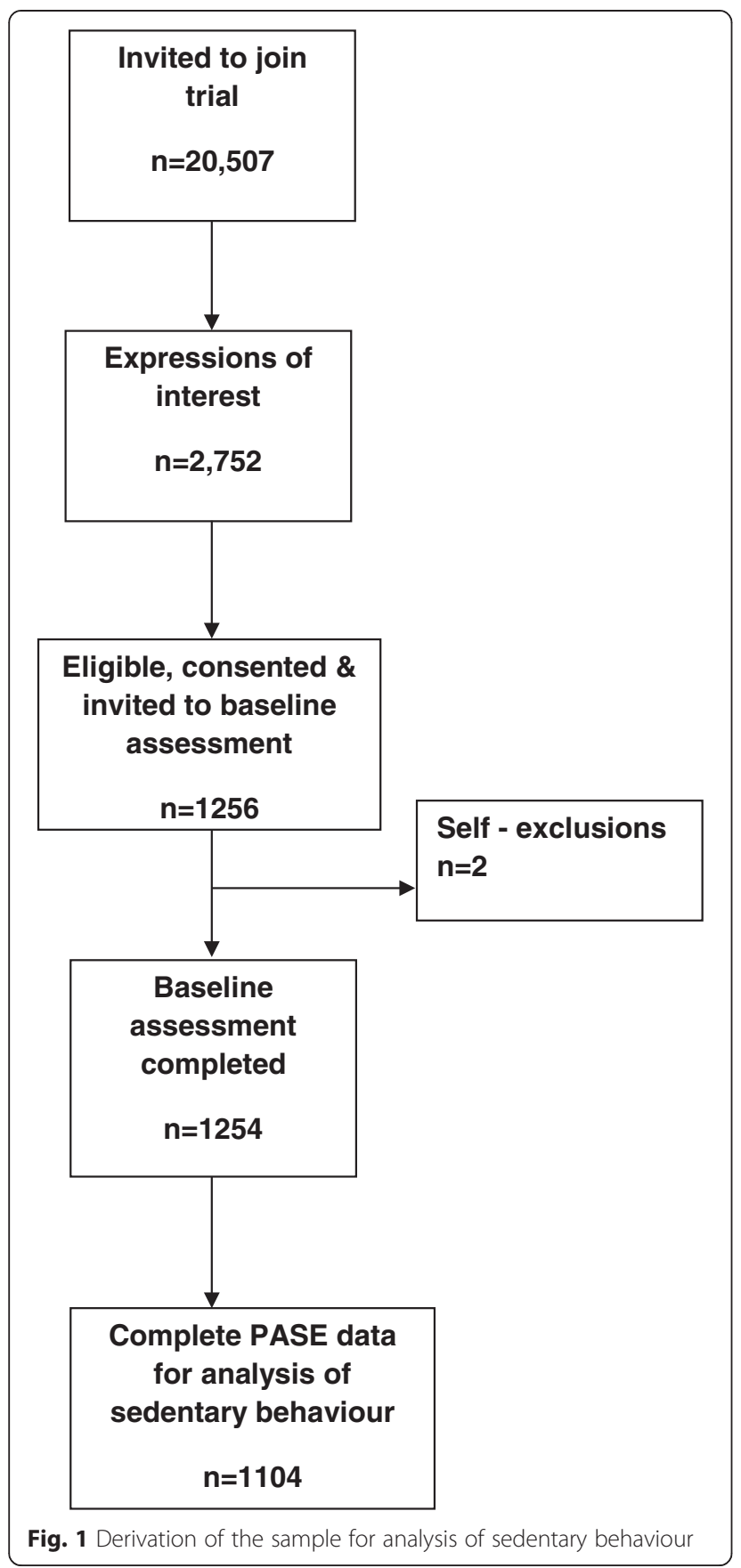

health. Age was dichotomised to capture the distinction between the 'younger' (65-74) and 'older' (75 and over) old.

Continuous variablets included 30-s chair stand, timed up \& go test in seconds, functional reach, FICSIT (Frailty and Injuries: Cooperative Studies of Intervention Techniques) score (balance), activity limitation, number of comorbidities, number of medications, quality of life and SF12 scores (physical and mental component scores).
Table 1 Data sets obtained from ProAct65+ participants

\begin{tabular}{|c|c|c|}
\hline $\begin{array}{l}\text { Demographic } \\
\text { Data }\end{array}$ & $\begin{array}{l}\text { Objective Functional } \\
\text { assessments }\end{array}$ & $\begin{array}{l}\text { Self-rated Health status } \\
\text { function }\end{array}$ \\
\hline Age & 30 s chair rise & Everyday activity limitation \\
\hline Gender & $\begin{array}{l}\text { Timed get-up \& go } \\
\text { test (TUG) }\end{array}$ & Comorbidities \\
\hline $\begin{array}{l}\text { Body Mass } \\
\text { Index (BMI) }\end{array}$ & Functional reach & Medication usage \\
\hline Smoking status & $\begin{array}{l}\text { Modified Clinical } \\
\text { Romberg (FICSIT) }\end{array}$ & Informal home help \\
\hline $\begin{array}{l}\text { Household } \\
\text { composition }\end{array}$ & & $\begin{array}{l}\text { Current level of physical } \\
\text { activity }\end{array}$ \\
\hline Education data & & $\begin{array}{l}\text { PHQ (Physical Health } \\
\text { Questionnaire) }\end{array}$ \\
\hline $\begin{array}{l}\text { Household } \\
\text { income }\end{array}$ & & $\begin{array}{l}\text { Perceived physical \& mental } \\
\text { health (SF-12) }\end{array}$ \\
\hline $\begin{array}{l}\text { Employment } \\
\text { status }\end{array}$ & & $\begin{array}{l}\text { Older People's Quality of Life } \\
\text { Questionnaire (OPQOL) }\end{array}$ \\
\hline
\end{tabular}

\section{Data analysis}

Baseline characteristics of ProAct65+ participants were compared with their sedentary behaviour status using chi-squared univariable analyses for dichotomised variables and logistic regression for continuous variables. Backwards stepwise elimination logistic regression analysis (Wald) was chosen as suitable for an exploratory study in a large sample, and was used to adjust for correlations between characteristics that were significant on univariable analysis. Results are presented as unadjusted and adjusted Odds Ratios with $95 \%$ confidence intervals.

\section{Results}

Three hundred eighty seven of the 1104 participants (35\%) were sedentary at baseline. Table 3 shows the associations between participant characteristics and sedentary behaviour, with each association presented unadjusted and adjusted for all other characteristics.

In this study sample, sedentary behaviour was not significantly different between men and women, and was not more common amongst those aged 75 and over than those 65-74. SB was associated with having an abnormal BMI $(<18.5$ or $>25)$ and $64 \%$ of the sample had abnormal BMIs. Only 18 of the sample had BMI values below 18.5, but $44 \%$ were sedentary; $42 \%$ of the 625 participants with BMI $>25 \mathrm{~kg} / \mathrm{m}^{2}$ were sedentary.

Univariable analyses showed that those who were sedentary were more likely to: ever have smoked, have more comorbidities, take more medications, have difficulty using public transport, use a walking aid, not live in a couple, have informal home help, and describe themselves as inactive. The sedentary reported greater activity 
Table 2 Description of characteristics examined

\begin{tabular}{|c|c|c|}
\hline Characteristic & Groups & \\
\hline CODED & 0 & 1 \\
\hline Sedentary & No & $\begin{array}{l}\text { Yes (sitting }>4 \text { h/day, }> \\
5 \text { days/week) }\end{array}$ \\
\hline \multicolumn{3}{|l|}{ Demographic Data } \\
\hline Age & $65-74$ & 75 years and over \\
\hline Gender & Male & Female \\
\hline BMI & Normal & Not normal $(<18.5,>25)$ \\
\hline Smoking status & Never & Ever (current/ex) \\
\hline $\begin{array}{l}\text { Household } \\
\text { composition }\end{array}$ & $\begin{array}{l}\text { Living as a couple } \\
\text { (married/co- } \\
\text { habiting) }\end{array}$ & $\begin{array}{l}\text { Not living as a couple } \\
\text { (alone/extended family/ } \\
\text { other) }\end{array}$ \\
\hline $\begin{array}{l}\text { Highest Educational } \\
\text { Level }\end{array}$ & Higher (FE \& Uni) & School only \\
\hline $\begin{array}{l}\text { Household pre-tax } \\
\text { income/annum } \\
\text { (GBP) }\end{array}$ & $\begin{array}{l}\text { Categorical } \\
\text { continuous }\end{array}$ & \\
\hline Employment status & Employed & Unemployed \\
\hline \multicolumn{3}{|l|}{ Functional Assessments } \\
\hline 30-s Chair stand [42] & Continuous & $\begin{array}{l}\text { More stands = better } \\
\text { function }\end{array}$ \\
\hline TUG (falls risk) [43] & Continuous & Faster $=$ better function \\
\hline $\begin{array}{l}\text { Functional reach } \\
(\mathrm{cm}) \text { [44] }\end{array}$ & Continuous & Further $=$ better function \\
\hline FICSIT balance scale & Continuous & $\begin{array}{l}\text { Higher score = better } \\
\text { balance }\end{array}$ \\
\hline \multicolumn{3}{|c|}{ Health Status \& Self-rated function } \\
\hline $\begin{array}{l}\text { Activity limitation } \\
\text { (days/month) }\end{array}$ & Continuous & 0-31 days/month \\
\hline $\begin{array}{l}\text { Number of } \\
\text { comorbidities }\end{array}$ & Continuous & Integer values \\
\hline $\begin{array}{l}\text { Number of } \\
\text { medications }\end{array}$ & Continuous & Integer values \\
\hline Informal home help & Absence & Presence \\
\hline $\begin{array}{l}\text { Current level of } \\
\text { activity }\end{array}$ & Some & None \\
\hline $\begin{array}{l}\text { Easy public transport } \\
\text { use (PHQ) }\end{array}$ & Yes & No \\
\hline $\begin{array}{l}\text { Use of walking aid } \\
\text { (PHQ) }\end{array}$ & No & Yes \\
\hline $\begin{array}{l}\text { Any falls in the past } \\
\text { year (PHQ) }\end{array}$ & No & Yes \\
\hline SF-12-PCS [45-47] & Continuous & $\begin{array}{l}\text { Higher score = better } \\
\text { health }\end{array}$ \\
\hline SF-12-MCS [45-47] & Continuous & $\begin{array}{l}\text { Higher score = better } \\
\text { health }\end{array}$ \\
\hline $\begin{array}{l}\text { Lubben social } \\
\text { network }\end{array}$ & Continuous & \\
\hline OPQOL [48] & Continuous & $\begin{array}{l}\text { Higher score = better } \\
\text { quality of life }\end{array}$ \\
\hline FESI [49] & Continuous & $\begin{array}{l}\text { Higher score = more falls } \\
\text { concern }\end{array}$ \\
\hline
\end{tabular}

limitation, poorer quality of life and poorer physical health as well as performing less well on some functional tests; timed up and go \& chair stand. There were no statistically significant associations between sedentary behaviour and educational attainment, household income, employment status, falls in the last year, falls risk (Falls Risk Assessment Tool, FRAT), functional reach, balance (FICSIT), self-reported mental health (SF12mental component score (Mental Component Score, MCS) and social isolation (Lubben social network score). These variables were excluded from further analysis. Table 3 shows the associations between sedentariness and continuous variables, and dichotomised variables.

Logistic regression analyses showed that only 4 covariates remained independently significantly associated with sedentary behaviour:

1. Abnormal BMI (OR 1.740 CI 1.248-2.425, $p=0.001$ ),

2. Ever smoked (OR 1.420, CI 1.043-1.934, $p=0.03$ ),

3. Number of medications taken (OR 1.069, CI 1.016$1.124, p<0.001)$,

4. Self-reported physical health (SF12-PCS) (OR 0.961, CI 0.933-0.990, $p<0.001$ ).

For each additional medication the odds of being sedentary increased and for each additional point on the SF-12 PCS (indicating better self-rated health) the odds of being sedentary decreased.

\section{Discussion}

\section{What this study shows}

The offer of exercise promotion did not just attract an already healthy, active group of older people. Almost half (42\%) of older adults recruited to this intervention study were sedentary by our definition and could therefore benefit from increasing their activity levels. To our knowledge the characteristics of thisrgroup of sedentary older people who engaged with exercise promotion has not been examined previously on this scale in the UK.

Sedentary participants in our exercise programme were different to sedentary older people described by epidemiological studies. In our sample of older people joining an exercise trial sedentariness was not associated with age, education, income, gender or functional fitness; this is not surprising, given that trial participants tend to be healthier than the general population. In this sample four characteristics were associated with sedentary behaviour; abnormal BMI, smoking status, self-reported physical health and multiple medication use. Ever smoking, abnormal BMI, multiple medication usage and poor self-reported physical health are markers of poor health. Smoking predicts cardiovascular disease, whilst selfreported limitation is more predictive of future adverse outcomes including mortality than the objective number 
Table 3 Unadjusted odds ratios showing associations between continuous and dichotomised variables and sedentary behaviour

\begin{tabular}{|c|c|c|c|c|c|c|c|}
\hline Continuous variable & Description & $\begin{array}{l}\text { Non-sedentary: mean } \\
\text { (s.d.) }\end{array}$ & $\begin{array}{l}\text { Sedentary: mean } \\
\text { (s.d.) }\end{array}$ & OR & $\begin{array}{l}\text { Lower } \\
\mathrm{Cl}\end{array}$ & $\begin{array}{l}\text { Upper } \\
\mathrm{Cl}\end{array}$ & $P$-value \\
\hline SF12_PCS $^{a} n=1049$ & Total score OR for each extra point & $37.54(5.98) n=664$ & $35.91(7.21) n=385$ & 0.962 & 0.943 & 0.980 & $<0.001$ \\
\hline No. of medications $n=1047$ & OR for each additional medication & $3.74(3.20) n=663$ & $4.49(3.26) n=384$ & 1.073 & 1.032 & 1.115 & $<0.001$ \\
\hline No. of comorbidities $n=1053$ & OR for each additional comorbidity & $1.93(1.54) n=666$ & $2.34(1.61) n=387$ & 1.174 & 1.086 & 1.271 & $<0.001$ \\
\hline Activity limitation $n=1054$ & $\begin{array}{l}\text { Self-reported no. of days limited per month OR for each additional day } \\
\text { limited }\end{array}$ & $1.01(4.60) n=667$ & $2.09(7.10) n=387$ & 1.033 & 1.010 & 1.056 & 0.004 \\
\hline Timed Up \& Go (TUG) $n=968$ & Duration in seconds OR for each extra second taken to complete task & $10.54(4.57) n=608$ & $11.46(6.63) n=360$ & 1.032 & 1.006 & 1.059 & 0.01 \\
\hline $30 \mathrm{~s}$ Chair stand $n=1033$ & Number in $30 \mathrm{~s}$ OR for each additional chair stand & $10.66(3.25) n=657$ & $10.14(3.37) n=376$ & 0.951 & 0.915 & 0.990 & 0.01 \\
\hline Quality of Life $e^{b}=999$ & Total score OR for each extra point & $130.75(13.23) n=662$ & $128.73(13.30) n=337$ & 0.989 & 0.978 & 0.999 & 0.03 \\
\hline SF12_MCS $n=1050$ & Total score OR for each extra point & $48.94(5.85) n=663$ & $49.31(6.31) n=386$ & 0.984 & 0.964 & 1.005 & 0.13 \\
\hline Functional reach $n=1017$ & Functional reach in $\mathrm{cms} O R$ for each additional $\mathrm{cm}$ reached & $26.02(7.97) n=642$ & $25.29(8.02) n=375$ & 0.988 & 0.979 & 0.999 & 0.15 \\
\hline FICSIT $^{d} n=1057$ & $\begin{array}{l}\text { Score } 0-28 \text { OR for each additional } \\
\text { point scored }\end{array}$ & $20.54(6.84) n=667$ & $19.91(7.33) n=390$ & 0.987 & 0.973 & 1.005 & 0.15 \\
\hline Dichotomised Variable & Category & Not sedentary $n(\%)$ & Sedentary n (\%) & OR & $\begin{array}{l}\text { Lower } \\
\mathrm{Cl}\end{array}$ & $\begin{array}{l}\text { Upper } \\
\mathrm{Cl}\end{array}$ & $P$-value \\
\hline \multirow[t]{2}{*}{ Age $n=1052$} & $65-74$ & $428(63.4)$ & $247(36.6)$ & 1.024 & 0.788 & 1.329 & 0.86 \\
\hline & $75+$ years & $237(62.9)$ & $140(37.1)$ & & & & \\
\hline \multirow[t]{2}{*}{ Gender $n=1053$} & Male & $241(61.5)$ & $151(38.5)$ & 0.886 & 0.685 & 1.147 & 0.36 \\
\hline & Female & $425(64.3)$ & $236(35.7)$ & & & & \\
\hline \multirow[t]{2}{*}{ BMI $n=1008$} & Normal & $266(72.9)$ & $99(27.1)$ & 1.982 & 1.500 & 2.620 & $<0.001$ \\
\hline & Abnormal & $370(57.5)$ & $273(42.5)$ & & & & \\
\hline \multirow[t]{2}{*}{ Smoking $n=1053$} & Never & $353(67.5)$ & $170(32.5)$ & 1.440 & 1.119 & 1.852 & 0.005 \\
\hline & Ever (ex/current) & $313(59.1)$ & $217(40.9)$ & & & & \\
\hline \multirow[t]{2}{*}{ Living circumstances $n=1051$} & As a couple & $405(65.6)$ & $212(34.4)$ & 1.291 & 1.002 & 1.664 & 0.05 \\
\hline & Not as a couple & $259(59.7)$ & $175(40.3)$ & & & & \\
\hline \multirow[t]{2}{*}{ Informal home help $n=1047$} & Absence & $625(64.4)$ & $346(35.6)$ & 2.007 & 1.256 & 3.208 & 0.003 \\
\hline & Presence & $36(47.4)$ & $40(52.6)$ & & & & \\
\hline \multirow[t]{2}{*}{ Current activity level $n=1005$} & Some & $392(66.1)$ & $201(33.9)$ & 1.356 & 1.046 & 1.759 & 0.02 \\
\hline & None & $243(59.0)$ & $169(41.0)$ & & & & \\
\hline \multirow[t]{2}{*}{ Public transport use $n=1047$} & Yes (easy) & $634(64.0)$ & $357(36.0)$ & 1.907 & 1.112 & 3.273 & 0.02 \\
\hline & No (not easy) & $27(48.2)$ & $29(51.8)$ & & & & \\
\hline \multirow[t]{2}{*}{ Walking aid used? $n=1052$} & No & $586(65.0)$ & $315(35.0)$ & 1.302 & 1.094 & 1.549 & 0.003 \\
\hline & Yes & $79(52.3)$ & $72(47.7)$ & & & & \\
\hline Employment status $n=1048$ & Employed & $56(62.9)$ & $33(37.1)$ & 0.984 & 0.628 & 1.543 & 0.94 \\
\hline
\end{tabular}


Table 3 Unadjusted odds ratios showing associations between continuous and dichotomised variables and sedentary behaviour (Continued)

\begin{tabular}{|c|c|c|c|c|c|c|c|}
\hline & Not employed & $607(63.3)$ & $352(36.7)$ & & & & \\
\hline \multirow[t]{2}{*}{ Educational level $n=1038$} & FE \& University & $304(64.3)$ & $169(35.7)$ & 1.097 & 0.851 & 1.413 & 0.48 \\
\hline & School only & $351(62.1)$ & $214(37.9)$ & & & & \\
\hline \multirow{5}{*}{$\begin{array}{l}\text { Household income (categorical linear) } \\
n=913\end{array}$} & Up to $£ 12,000$ & $159(56.8)$ & $121(43.2)$ & - & - & - & 0.13 \\
\hline & $£ 12,001-20,000$ & $168(64.1)$ & 94 (35.9) & 0.735 & 0.520 & 1.039 & 0.08 \\
\hline & $£ 20,001-30,000$ & $133(65.5)$ & $70(34.5)$ & 0.692 & 0.476 & 1.005 & 0.05 \\
\hline & $£ 30,001-45,000$ & $66(69.5)$ & $29(30.5)$ & 0.577 & 0.351 & 0.949 & 0.03 \\
\hline & $>£ 45,001$ & $44(60.3)$ & 29 (39.7) & 0.866 & 0.512 & 1.464 & 0.59 \\
\hline
\end{tabular}

Varying denominators reflect variations in data capture

ahigher score $=$ better physical function

${ }^{b}$ higher score $=$ better self-rated quality of life

chigher score $=$ better self-reported mental health

dhigher score $=$ better balance 
of comorbidities [40,41]. Use of multiple medication use is not the same as having comorbidities, in this sample. Overall, the sedentary people in this trial were in poor health but nevertheless interested in increasing their physical activity.

\section{Strengths and limitations}

Our study's strengths include the large number of participants enrolled who are sedentary and our ability to characterise that cohort in detail. Additionally it was able to focus on sedentary behaviour even in those who were physically active.

We are limited by the secondary analysis of data from the pre-existing ProAct65+ trial. As such, our sedentary score is an estimate from the PASE questionnaire and not from a dedicated assessment tool for sedentariness, nor from an objective measurement. The trial excluded participants if they were frequent fallers or had poor mobility prior to the offer of participation in the exercise programme, making it likely that some of the most sedentary older adults were excluded from the trial. This self-selected population cannot be thought of as a typical of the wider population of sedentary older people, and we cannot estimate the number of sedentary and nonsedentary individuals among the 20,507 people initially invited to the trial. Any stepwise analysis could result in a combination of predictor variables that apply only to that dataset, and so such results need to be replicated in an independent dataset.

\section{Implications for practice and research}

Our sedentary group had good grounds for wanting to increase their activity levels. They are already experiencing ill health as evidenced by their medication use, self-rated physical health, smoking status and abnormal BMI. This study suggests that some sedentary older people who would benefit from exercise promotion would join exercise promotion interventions organised through General Practice. Further investigation of the impact of exercise promotion on sedentariness is required as recent studies have had short follow ups [34-36]. Longer term studies examining the effect of exercise promotion on a group of sedentary older adults are required.

\section{Conclusion}

Offering exercise opportunities to older people does attract some sedentary participants with a poor health profile (characterised above) who are likely to benefit from such intervention.

\footnotetext{
Abbreviations

SB: Sedentary behaviour; PASE: Physical activity scale for the elderly; MVPA: Moderately-vigorous physical activity; FaME: Falls management exercise programme; OEP: Otago exercise programme; TAU: Treatment as usual; FICSIT: Frailty and Injuries: Cooperative Studies of Intervention
}

Techniques; FRAT: Falls risk assessment tool; MCS: Mental component score; PCS: Physical component score; OPQOL: Older people's quality of life questionnaire; TUG: Timed get-up and go test; FES-I: Falls efficacy scaleinternational; PHQ: Physical health questionnaire; BMI: Body mass index.

\section{Competing interests}

The authors declare that they have no competing interests.

\section{Authors' contributions}

$\mathrm{RH} \& \mathrm{SI}$ conceived of and carried out the secondary analysis. DAS, DK, TM helped to draft the manuscript. RWM provided statistical support. All authors read and approved the final manuscript.

\section{Acknowledgement}

We thank all the practices and participants who took part in the original study.

\section{Author details}

'Department of Primary Care \& Population Health, University College London, Royal Free Campus, Rowland Hill St., London NW3 2PF, UK. ${ }^{2}$ School of Social and Community Medicine, University of Bristol, Canynge Hall, 39 Whatley Road, Bristol BS8 2PS, UK. ${ }^{3}$ Division of Primary Care, University of Nottingham, Floor 13, Tower Building, University Park, Nottingham NG7 2RD, UK. ${ }^{4}$ School of Health \& Life Sciences, Glasgow Caledonian University, Cowcaddens Rd, Glasgow, Lanarkshire G4 OBA, UK. ${ }^{5}$ Nottingham University Hospital NHS Trust, Derby Rd, Nottingham NG7 2UH, UK.

Received: 12 March 2015 Accepted: 20 May 2015

Published online: 28 May 2015

\section{References}

1. Sedentary Behaviour Research N. Letter to the editor: standardized use of the terms "sedentary" and "sedentary behaviours". Appl Physiol Nutr Metab. 2012;37(3):540-2.

2. de Rezende LFM, Rey-Lopez JP, Matsudo VKR, do Carmo Luiz O. Sedentary behavior and health outcomes among older adults: a systematic review. BMC Public Health. 2014;14(1):333.

3. Grontved A, Hu FB. Television viewing and risk of type 2 diabetes, cardiovascular disease, and all-cause mortality: a meta-analysis. Jama. 2011;305(23):2448-55.

4. Department of Health U. Start Active, Stay Active: A report on physical activity for health from the four home countries' Chief Medical Officers. 2011.

5. Health BHFCFPAa. Sedentary Behaviour evidence briefing. 2012.

6. Owen N, Healy GN, Matthews CE, Dunstan DW. Too much sitting: the population health science of sedentary behavior. Exer Sport Sci Rev. 2010;38(3):105-13.

7. Davis MG, Fox KR, Hillsdon M, Sharp DJ, Coulson JC, Thompson JL. Objectively measured physical activity in a diverse sample of older urban UK adults. Med Sci Sports Exerc. 2011:43(4):647-54.

8. Bennie JA, Chau JY, van der Ploeg HP, Stamatakis E, Do A, Bauman A. The prevalence and correlates of sitting in European adults-a comparison of 32 Eurobarometer-participating countries. Int. 2013;10:107.

9. Bankoski A, Harris TB, McClain JJ, Brychta RJ, Caserotti P, Chen KY, et al. Sedentary activity associated with metabolic syndrome independent of physical activity. Diabetes Care. 2011;34(2):497-503.

10. Gardiner PA, Healy GN, Eakin EG, Clark BK, Dunstan DW, Shaw JE, et al. Associations between television viewing time and overall sitting time with the metabolic syndrome in older men and women: the Australian Diabetes, Obesity and Lifestyle study. J Am Geriatr Soc. 2011;59(5):788-96.

11. Gennuso KP, Gangnon RE, Matthews CE, Thraen-Borowski KM, Colbert LH. Sedentary behavior, physical activity, and markers of health in older adults. Med Sci Sports Exerc. 2013;45(8):1493-500.

12. van der Berg JD, Bosma H, Caserotti P, Eiriksdottir G, Arnardottir NY, Martin KR, Brychta RJ, Chen KY, Sveinsson T, Johannsson E, Launer LJ, Gudnason V, Jonsson PV, Stehouwer CDA, Harris TB, Koster A. Midlife determinants assoicated with sedentary behaviour in old age. Med Sci Sports Exer. 2014; 46(7):1359-65

13. Seguin R, Lamonte M, Tinker L, Liu J, Woods N, Michael YL, et al. Sedentary Behavior and Physical Function Decline in Older Women: Findings from the Women's Health Initiative. J Aging Res. 2012;2012:271589.

14. Chastin SFM, Mandrichenko O, Helbostadt JL, Skelton DA. Associations between objectively-measured sedentary behaviour and physical activity 
with bone mineral density in adults and older adults, the NHANES study. Bone. 2014;64:254-62.

15. Katzmarzyk PT, Church TS, Craig CL, Bouchard C. Sitting time and mortality from all causes, cardiovascular disease, and cancer. Med Sci Sports Exerc. 2009:41(5):998-1005.

16. Kaplan MS, Huguet N, Newsom JT, McFarland BH. Characteristics of physically inactive older adults with arthritis: results of a population-based study. Prev Med. 2003;37(1):61-7.

17. Dogra S, Stathokostas L. Sedentary behavior and physical activity are independent predictors of successful aging in middle-aged and older adults. J Aging Res. 2012;2012:190654.

18. Strath SJ, Schwartz AM, Cashin SE. Ambulatory physical activity profiles of older adults. J Aging Phys Activity. 2009;17(1):46-56.

19. Kikuchi H, Inoue S, Sugiyama T, Owen N, Oka K, Shimomitsu T. Correlates of prolonged television viewing time in older Japanese men and women. BMC Public Health. 2013;13:213.

20. Inoue S, Sugiyama T, Takamiya T, Oka K, Owen N, Shimomitsu T. Television viewing time is associated with overweight/obesity among older adults, independent of meeting physical activity and health guidelines. J Epidemiol. 2012;22(1):50-6.

21. Chastin SFM, Fitzpatrick N, Andrews M, DiCroce N. Determinants of sedentary behavior, motivation, barriers and strategies to reduce sitting time in older women: a qualitative investigation. Int J Environ Res Public Health. 2014;11(1):773-91.

22. Arnardottir NY, Koster A, Van Domelen DR, Brychta RJ, Caserotti P, Eiriksdottir $\mathrm{G}$, et al. Objective measurements of daily physical activity patterns and sedentary behaviour in older adults: Age, Gene/Environment Susceptibility-Reykjavik Study. Age Ageing. 2013;42(2):222-9.

23. Harvey JA, Chastin SFM, Skelton DA. Prevalence of sedentary behaviour in older adults: a systematic review. Int J Environ Res Public Health. 2013;10:6645-61.

24. Stamatakis E, Davis M, Stathi A, Hamer M. Associations between multiple indicators of objectively-measured and self-reported sedentary behaviour and cardiometabolic risk in older adults. Prev Med. 2012;54(1):82-7.

25. Matthews CE, Chen KY, Freedson PS, Buchowski MS, Beech BM, Pate RR, et al. Amount of time spent in sedentary behaviors in the United States, 2003-2004. Am J Epidemiol. 2008;167(7):875-81.

26. van der Ploeg HP, Chey T, Korda RJ, Banks E, Bauman A. Sitting time and all-cause mortality risk in 222497 Australian adults. Arch Intern Med. 2012;172(6):494-500.

27. Tudor-Locke CE, Myers AM. Challenges and opportunities for measuring physical activity in sedentary adults. Sports Med. 2001:31(2):91-100.

28. Espana-Romero V, Golubic R, Martin KR, Hardy R, Ekelund U, Kuh D, et al. Comparison of the EPIC Physical Activity Questionnaire with combined heart rate and movement sensing in a nationally representative sample of older British adults. PLoS One. 2014;9(2):e87085.

29. van Uffelen JGZ, Heesch KC, Hill RL, Brown WJ. A qualitative study of older adults' responses to sitting-time questions: do we get the information we want? BMC Public Health. 2011;11:458.

30. Visser M, Koster A. Development of a questionnaire to assess sedentary time in older persons-a comparitive study using accelerometry. BMC Geriatr. 2013;13(80):1471-2318.

31. Buman MP, Hekler EB, Haskell WL, Pruitt L, Conway TL, Cain KL, et al. Objective light-intensity physical activity associations with rated health in older adults. Am J Epidemiol. 2010;172(10):1155-65.

32. Pate RR, O'Neill JR, Lobelo F. The evolving definition of "sedentary". Exerc Sport Sci Rev. 2008;36(4):173-8

33. Healy GN, Dunstan DW, Salmon J, Cerin E, Shaw JE, Zimmet PZ, et al. Breaks in sedentary time: beneficial associations with metabolic risk. Diabetes Care. 2008;31(4):661-6.

34. Fitzsimons CF, Kirk A, Baker G, Michie F, Kane C, Mutrie N. Using an individualised consultation and activPAL feedback to reduce sedentary time in older Scottish adults: results of a feasibility and pilot study. Prev Med. 2013:57(5):718-20.

35. Gardiner PA, Eakin EG, Healy GN, Owen N. Feasibility of reducing older adults' sedentary time. Am J Prev Med. 2011;41(2):174-7.

36. Magistro D, Liubicich ME, Candela F, Ciairano S. Effect of ecological walking training in sedentary elderly people: act on aging study. Gerontologist. 2014;54(4):611-23.
37. Stevens Z, Barlow C, Kendrick D, Masud T, Skelton DA, Dinan-Young S. Effectiveness of general practice-based physical activity promotion for older adults: systematic review. Prim Health Care Res Dev. 2014;15(2):190-201.

38. Niffe S, Kendrick D, Morris R, Skelton D, Gage H, Dinan S, et al. Multi-centre cluster randomised trial comparing a community group exercise programme with home based exercise with usual care for people aged 65 and over in primary care: protocol of the ProAct 65+ trial. Trials. 2010;11(1):6.

39. Nliffe S, Kendrick D, Morris R, Masud T, Gage H, Skelton D, et al. Multicentre cluster randomised trial comparing a community group exercise programme and home-based exercise with usual care for people aged 65 years and over in primary care. Health Technol Assess. 2014;18(49):1-105.

40. Idler EL, Benyamini Y. Self-rated health and mortality: a review of twenty-seven community studies. J Health Soc Behav. 1997;38(1):21-37.

41. DeSalvo KB, Bloser N, Reynolds K, He J, Muntner P. Mortality prediction with a single general self-rated health question. A meta-analysis. J Gen Intern Med. 2006;21(3):267-75.

42. Rikli RE, Jones CJ. Functional fitness normative scores for communityresiding older adults aged 60-94. J Aging Phys Act. 1999;7:162-81.

43. Bohannon RW. Reference values for the timed up and go test: a descriptive meta-analysis. J Geriatr Phys Ther. 2006;29(2):64-8.

44. Duncan PW, Weiner DK, Chandler J, Studenski S. Functional reach: a new clinical measure of balance. J Gerontol. 1990;45(6):M192-7.

45. Jenkinson C, Chandola T, Coulter A, Bruster S. An assessment of the construct validity of the SF-12 summary scores across ethnic groups. J Public Health Med. 2001;23(3):187-94.

46. Mols F, Pelle AJ, Kupper N. Normative data of the SF-12 health survey with validation using postmyocardial infarction patients in the Dutch population. Qual Life Res. 2009:18(4):403-14.

47. Reeder BA, Chad KE, Harrison EL, Ashworth NL, Sheppard MS, Fisher KL, et al. Saskatoon in motion: class- versus home-based exercise intervention for older adults with chronic health conditions. J Phys Act Health. 2008:5(1):74-87.

48. Bowling A, lliffe S. Psychological approach to successful ageing predicts future quality of life in older adults. Health Qual Life Outcomes. 2011;9:13.

49. Yardley L, Donovan-Hall M, Francis K, Todd C. Attitudes and beliefs that predict older people's intention to undertake strength and balance training. J Gerontol B Psychol Sci Soc Sci. 2007;62(2):119-25.

\section{Submit your next manuscript to BioMed Central and take full advantage of:}

- Convenient online submission

- Thorough peer review

- No space constraints or color figure charges

- Immediate publication on acceptance

- Inclusion in PubMed, CAS, Scopus and Google Scholar

- Research which is freely available for redistribution 